\title{
EFFECT OF EXTRACTION SOLVENTS ON THE BIOMOLECULES AND ANTIOXIDANT PROPERTIES OF SCORZONERA UNDULATA (ASTERACEAE): APPLICATION OF FACTORIAL DESIGN OPTIMIZATION PHENOLIC EXTRACTION
}

\author{
Khaled Athmouni ${ }^{1,2}$, Taheni Belghith ${ }^{1,2}$, Khaled Bellassouad², Abdelfattah El Feki², \\ Habib Ayadi ${ }^{1}$
}

${ }^{1}$ Research Unit UR 11 ES 72 / Biodiversity and Aquatic Ecosystems, Department of Life Sciences, University of Sfax Road Soukra Km 3,5, B.P. 1171, CP 3000 Sfax, Tunisia

${ }^{2}$ Laboratory of Animal Ecophysiology, Faculty of Sciences of Sfax, University of Sfax

P.O. Box 95, Sfax 3000, Tunisia

\begin{abstract}
Background. Phenolic compounds were extracted and isolated from S. undulata roots.

Methods. Sample of roots from E. hirta was tested for phenolic compounds, and in vitro antioxidant activity by diphenyl-1-picrylhydrazyl (DPPH) assay, ABTS, FRAP and reducing power was measured using cyanoferrate method.

Results. The methanolic fraction exhibited the highest total phenol content (6.12 $\pm 0.11 \mathrm{mg}$ AGE/g DW). On the other hand, the highest flavonoids concentration was observed in ethyl acetate fraction $(2.90 \pm 0.05 \mathrm{mg}$ $\mathrm{CE} / \mathrm{g} \mathrm{DW})$ in addition to anthocyanins $(28.56 \pm 3.96 \mathrm{mg} / \mathrm{l})$. Besides, the highest level of tannins content was measured in the polar aprotic solvent ethyl acetate extract $(3.25 \pm 0.06 \mathrm{mg} \mathrm{CE} / \mathrm{g} \mathrm{DW})$. The different extracts of $S$. undulata were evaluated for their radical scavenging activities by means of the DPPH assay. The strongest scavenging activity was observed in methanolic fraction scavenged radicals effectively with $\mathrm{IC}_{50}$ values of $0.14 \pm 0.02 \mathrm{mg} / \mathrm{ml}$. Similarly, the potassium ferricyanide reduction (FRAP) and ABTS ${ }^{\cdot+}$ of methanol extract. On the other hand, the total reducing power of ethyl acetate extract was found higher than of other extracts. This paper presents the application of the design-of experiment method for optimizing the extraction of phenolic content using methanol solvent. The resulting regression model has shown that the effect of temperature is not statistically significant (with $>95 \%$ certainty), while that of agitation speed is. The two main effects are contributed by the solvent concentration and the maceration period.

Conclusion. Our results clearly showed that the extraction of phenolic compounds and their antioxidant capacity is significantly affected by solvent combinations. $S$. undulata presented the highest total phenolic content, total flavonoids content and antioxidant capacity values. The resulting regression model has shown that the effect of temperature is not statistically significant (with $>95 \%$ certainty), while that of agitation speed is.
\end{abstract}

Key words: antioxidant activity, S. undulata roots, extracting solvents, phenolic content, solvent polarity, factorial design 

oxidant properties of Scorzonera undulata (Asteraceae): Application of factorial design optimization phenolic extraction. Acta Sci. Pol. Technol. Aliment., 14(4), 313-330. DOI: 10.17306/J.AFS.2015.4.32

\section{INTRODUCTION}

Since prehistoric times, many medicinal plants have been used in folk medicine (Rout et al., 2000; Yesil-Celiktas et al., 2007; Guo et al., 2007; Shinde et al., 2010). They have been used all over the world for thousands of years as natural medicines possessing therapeutic and other pharmacologic effect. Today, according to the World Health Organization (WHO), as many as $80 \%$ of the world's population depend on traditional medicine for their primary health-care needs. The preliminary results of a study on behalf of WHO have shown that the number of individuals using medicinal plants is large and increasing, even among young people (WHO, IUCN and WWF, 1993). Medicinal plants or parts of them (leaves, rhizomes, roots, seeds, flowers) can be utilized in different forms such as fresh crude form and preparations as teas, decoctions, powdered plant material, or extracted forms of medicinal agents (juices, water or alcohol extracts, tinctures, essential oils, resins, balsams). Medicinal plants are generally known and popular for a number of health benefits such as blood pressure decreasing, prevention of cardiovascular diseases, or reducing the risk of cancer also due to their antioxidant activity (Burt, 2004; Suhaj, 2006; Brewer, 2011; Ghasemzadeh and Ghasemzadeh, 2011; Mothana, 2011; Prochazkova et al., 2011). The preservative effect of many plant spices and herbs suggests the presence of antioxidative and antimicrobial constituents in their tissues (Hirasa and Takemasa, 1998). Recently, interest has increased considerably in finding naturally occurring antioxidants for use in foods or medicinal materials to replace synthetic antioxidants, which are being restricted due to their carcinogenicity (Velioglu et al., 1998). The genus Scorzonera L. (Asteraceae) is a large genus with 160 species. It is widely spread in arid regions of Eurasia and North Africa. In recent years ethnobotanical, phytochemical and biological activity studies have been carried out in Scorzonera (Akkol et al., 2012). Scorzonera species are used against pulmonary diseases, colds, for the treatment of wounds and gastro-intestinal disorders, as well as for their stomachic, diuretic, galactagogue, antipyretic and appetizing effects in European traditional medicine (Zidorn et al., 2000, 2003; Tsevegsuren et al., 2007); used for the treatment of diarrhea, lung edema, parasitic diseases, and fever caused by bacterial and viral infections in Mongolian traditional medicine (Tsevegsuren et al., 2007); used for the treatment of hepatic pains in Libyan folkloric medicine (Auzi et al., 2007) and in Chinese and Tibetan folk medicine, have also medicinal usage in breast inflammation and abscess due to their antipyretic and anti-inflammatory activities (Zhu et al., 2009). Moreover, Scorzonera species are a rich source of dietary polyphenols such as flavonoids and phenolic acids including caffeoylquinic acid derivatives (Tsevegsuren et al., 2007; Zhu et al., 2009; Jehle 2010; Akkol et al., 2011; Sari, 2012; Wang et al., 2012; Yang et al., 2013; Milella et al., 2014). This genus has attracted the attention of researchers due to the many chemical classes of its secondary metabolites, including dihydroisocoumarins, stilbenes, lignans, phenolic derivatives, phtalides (Sari et al., 2007), coumarins, kavalactones (Jiang et al., 2007), sesquiterpenes (Zidorn, 2008), triterpenes (Wang et al., 2007), and flavonoids (Sareedenchai and Zidorn, 2010). Scorzonera undulata is perennial with a thick blackish stump and can be eaten in the spring, the leaves, are in clumps, with a narrow, very long limb that is wavy at the edge, glaucous, with very short woolly hairs. However, there is rare study on the effect of solvents with various polarities on extracting active compounds from Scorzonera undulata related to their antioxidant activities. Because, the determination of the best solvent extract for Scorzonera undulata with measurement of total phenolic content and various antioxidant activity assays was one important factor to increase the extraction process efficacy. The aim of this study was to examine the effect of different extracting solvents with different polarity on phenolic compounds and antioxidant activity (ferric reducing antioxidant power [FRAP], 2,2-diphenyl-1-picrylhydrazyl [DPPH] and 2,2-azino-bis-3-ethylbenzothiazoline-6-sulfonic acid [ABTS]) of Scorzonera undulata. The solvent that exhibited the highest phenolic content has been optimized. A two-levels factorial design was used to determine the most effective process parameters, and the effects of phenolic content in this plant. 


\section{MATERIAL AND METHODS}

\section{Plant materials}

Fresh roots from S. undulata were collected in May 2014 in Djebel Bou Ramli $\left(34^{\circ} 31^{\prime} 8^{\prime \prime} \mathrm{N}\right.$ and $\left.8^{\circ} 32^{\prime} 48^{\prime \prime} \mathrm{E}\right)$, Gafsa (South Tunisian). The plant was identified by Pr. Mohamed Chaieb, botanist at the University of Science (Sfax, Tunisia).

\section{Extraction procedure of biomolecule}

Methanolic fraction. The roots of $S$. undulata $(1 \mathrm{~g})$ were broken into small pieces and macerated in methanol $(20 \mathrm{ml})$ at room temperature for $48 \mathrm{~h}$. The extract was then separated from the residue by filtration through Whatman $0.45 \mu \mathrm{m}$ filter paper. The solvent was evaporated under vacuum at $60^{\circ} \mathrm{C}$. The residue was weighed and dissolved in methanol $(3 \mathrm{ml})$ for further analysis. Eventually, the solutions were stored at $-20^{\circ} \mathrm{C}$. The remaining aqueous solution was fractionated successively with n-hexane and ethyl acetate (Fig. 1).

\section{Chemicals and reagents}

Butylated hydroxytoluene (BHT), 2,2-diphenyl-1-picrylhydrazyl (DPPH), catechin, 2,4,6-tripyridyl-s-triazine (TPTZ), 6-hydroxy-2,5,7,8-tetramethylchroman-2-carboxylic acid (trolox) and 2,2-azinobis(3-ethylbenzothiazoline-6-sulfonic acid) diammonium salt (ABTS).

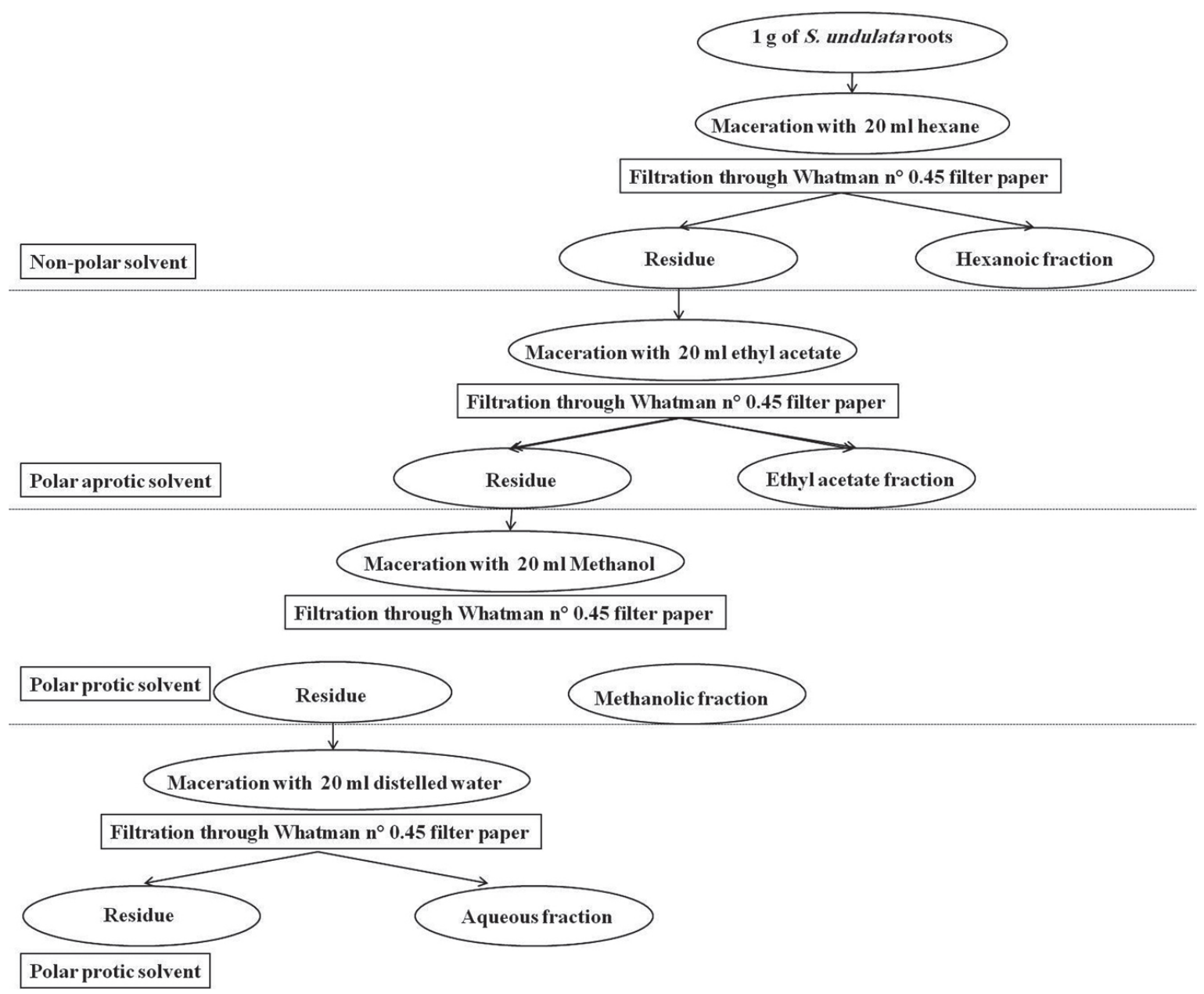

Fig. 1. Extraction procedure of biomolecule 

oxidant properties of Scorzonera undulata (Asteraceae): Application of factorial design optimization phenolic extraction. Acta Sci. Pol. Technol. Aliment., 14(4), 313-330. DOI: 10.17306/J.AFS.2015.4.32

\section{Determination of total phenolic content}

Total phenolics content of $S$. undulata was measured by Folin-Ciocalteu's phenol reagent (Singleton and Rossi, 1965; Kim et al., 2003). First, $200 \mathrm{ml}$ of appropriately diluted sample or gallic acid standard were added to $2.6 \mathrm{ml}$ of distilled deionized water. Then, $200 \mathrm{ml}$ of Folin-Ciocalteu's phenol reagent was added at time zero and mixed. After $6 \mathrm{~min}, 2 \mathrm{ml}$ of $7 \%(\mathrm{w} / \mathrm{v})$ $\mathrm{Na}_{2} \mathrm{CO}_{3}$ solution was added and mixed. After incubation for $90 \mathrm{~min}$ at room temperature, absorbance was measured at $750 \mathrm{~nm}$ versus a prepared blank. The blank consisted of $200 \mathrm{ml} \mathrm{50 \%} \mathrm{(v/v)} \mathrm{methanol} \mathrm{instead}$ of sample. Gallic acid in 50\% (v/v) methanol solution in concentrations of $0.1,0.3,0.5$, and $0.7 \mathrm{mg} / \mathrm{ml}$ was used as a standard and a calibration curve was drawn for each day of analysis. The content of total phenolics was expressed as mg gallic acid equivalent (GAE)/g of dry weight. All samples were analysed in triplicate.

\section{Total flavonoids content}

Total flavonoid content was measured according to the method of Zhishen et al. (1999). Sample extract was added with $0.3 \mathrm{ml}$ of $5 \%$ sodium nitrite and well mixed. After $5 \mathrm{~min}$ of incubation, $0.3 \mathrm{ml}$ of $10 \%$ aluminum chloride solution was added. Then, after $6 \mathrm{~min}, 2 \mathrm{ml}$ of $1 \mathrm{M}$ sodium hydroxide was added to the mixture and made up the volume to $10 \mathrm{ml}$ with water. The absorbance was measured at $510 \mathrm{~nm}$ with UV-visible spectrophotometer. Total flavonoids were measured from catechin $(0-0.3 \mathrm{mg})$ standard curve and expressed as $\mathrm{mg}$ catechin equivalents/g of dry weight.

\section{Determination of anthocyanins content}

Monomeric anthocyanin content of $S$. undulata was measured using a spectrophotometrically $\mathrm{pH}$ differential protocol according to (Broadhurst and Jones, 1978). Extracts were mixed thoroughly with $0.025 \mathrm{M}$ potassium chloride $\mathrm{pH} 1$ buffer and similarly with sodium acetate buffer $\mathrm{pH} 4.5$ in 1:10 ratio of extract to buffer. The absorbance of these solutions was measured at 510 and $700 \mathrm{~nm}$. The anthocyanin content was calculated as follows:

Total monomeric anthocyanins $(\mathrm{mg} / \mathrm{l})=$

$$
=A b s \times M W \times 1000 /(\varepsilon \times \mathrm{C})
$$

where:

$A b s-$ absorbance $=(\mathrm{A} 515-\mathrm{A} 700)_{\mathrm{pH} 1.0}-(\mathrm{A} 515-$
$\mathrm{A} 700)_{\mathrm{pH} 4.5}$,
$M W-$ molecular weight for cyanidin 3-glucoside
$=449.2$,
$\varepsilon-$ the molar absorptivity of cyanidin 3-glucoside
$=26900$,
$\mathrm{C}-$ the concentration of the buffer in milligrams
per milliliter.
Anthocyanin content was expressed as milligrams of cyanidin 3-glucoside equivalents 11 of the triplicate extracts.

\section{Determination of condensed tannins}

Condensed tannins content was determined by the vanillin method as described by Broadhurst and Jones (1978). $3 \mathrm{ml}$ of vanillin (4\% in methanol) were added to $0.5 \mathrm{ml}$ of the different extract. $1.5 \mathrm{ml}$ of highly concentrated $\mathrm{HCl}$ was then added. The mixture was then kept in the dark for $15 \mathrm{~min}$ at $20^{\circ} \mathrm{C}$. The absorbance was read at $500 \mathrm{~nm}$. A calibration curve was prepared with a solution of catechin. The results were obtained in $\mathrm{mg}$ of catechin equivalent per $\mathrm{g}$ of dry weight $(\mathrm{mg}$ CE/g DW).

\section{Determination of the antioxidant activity}

The antioxidant potential of $S$. undulata organic extracts was determined by radical scavenging assays: the 2,2-diphenylpicrylhydrazyl radical (DPPH'), FRAP, the 2,2'-azinobis3-ethylbenzothiazoline-6-sulfonic acid radical $\left(\mathrm{ABTS}^{++}\right)$and reducing power.

Free radical scavenging activity on 2,2-diphenyl-1-picrylhydrazyl (DPPH'). The free radical scavenging capability of each extract solution on DPPH radicals was determined as described previously $(\mathrm{Oz}-$ türk et al., 2011). Briefly, $4 \mathrm{ml}$ of methanol solution of DPPH $(0.1 \mathrm{mM})$ was mixed with $1 \mathrm{ml}$ of each of extract (methanol, n-hexane, water and ethyl acetate) solution at different concentrations $(0-0.4 \mathrm{mg} / \mathrm{ml})$. The reaction mixture was incubated in a dark room for $30 \mathrm{~min}$ and the free radical scavenging ability was estimated by measuring the absorbance at $515 \mathrm{~nm}$ with the spectrophotometer. The reaction was carried out in capped glass test tubes that were tightly wrapped with aluminum foil. The DPPH radical stock solution was freshly prepared every day for the reaction, and 
precautionary measures were taken to reduce the loss of free radical activity during the experiment. The inhibition percentage of DPPH radicals was calculated as:

Inhibition $(\%)$ of DPPH radicals $=A c-A s / A c \times 100$

where:

$A c$ - absorbance of the control reaction (all reagents except plant extract),

$A s$ - absorbance of the sample (plant extract).

Ferric reducing antioxidant power (FRAP) assay. The procedure described by Benzie and Strain was followed (Lahouel and Fillastre, 2004). The principle of this method is based on the reduction of a ferric-tripyridyltriazine complex to its ferrous, colored form in the presence of antioxidants. Briefly, the FRAP reagent contained $2.5 \mathrm{ml}$ of a $10 \mathrm{mmol} / 1 \mathrm{TPTZ}$ (2,4,6-tripyridy-s-triazine, Sigma) solution in $40 \mathrm{mmol} / \mathrm{l} \mathrm{HCl}$ plus $2.5 \mathrm{ml}$ of $20 \mathrm{mmol} / 1 \mathrm{FeCl}_{3}$ and $25 \mathrm{ml}$ of $0.3 \mathrm{~mol} / 1$ acetate buffer, $\mathrm{pH} 3.6$ and was prepared freshly and warmed at $37^{\circ} \mathrm{C}$. Aliquots of $40 \mu \mathrm{l}$ sample supernatant were mixed with $0.2 \mathrm{ml}$ distilled water and $1.8 \mathrm{ml}$ FRAP reagent and the absorbance of reaction mixture at $593 \mathrm{~nm}$ was measured spectrophotometrically after incubation at $37^{\circ} \mathrm{C}$ for $10 \mathrm{~min}$. Value of FRAP was expressed as Trolox equivalents per gram of dry weight (TE/g DW).

Free radical-scavenging ability by the use of ABTS radical cation (ABTS assay). Antioxidant activities of $S$. undulata were also analysed by investigating their ability to scavenge the $\mathrm{ABTS}^{-+}$free radical using a modified methodology previously reported by Ozgen et al. (2006). When combined with an oxidant (2.45 $\mathrm{mM}$ potassium persulfate), ABTS $(7 \mathrm{mM}$ in $20 \mathrm{mM}$ sodium acetate buffer, $\mathrm{pH} 4.5$ ) reacts to create a stable, dark blue-green radical solution following $12-16 \mathrm{~h}$ of incubation in the dark $\left(4^{\circ} \mathrm{C}\right)$. The solution was then diluted to an absorbance of $0.7 \pm 0.01$ at $734 \mathrm{~nm}$ to form the test reagent. Reaction mixtures containing $20 \mu \mathrm{l}$ of sample and $3 \mathrm{ml}$ of reagent were incubated in a water bath at $30^{\circ} \mathrm{C}$ for $30 \mathrm{~min}$. As unpaired electrons are sequestered by antioxidants in the sample the test solution turns colourless and the absorbance at $734 \mathrm{~nm}$ is reduced. The final result was expressed as $\mathrm{mM}$ of Trolox equivalents (TE) per $\mathrm{g}$ of dry weight (DW).
Reducing power. The ferric reducing antioxidant power assay was used to assess the reducing capacities of extracts of $S$. undulata. Different dilutions (0.05$0.5 \mathrm{mg} / \mathrm{ml}$ ) of each plant extract (ethyl acetate, methanol, n-hexane and water). Reducing power of both extracts of $S$. undulata were measured by method of Oyaizu's (1986) with a slight modification. According to this method, the reduction of $\mathrm{Fe}^{3+}$ to $\mathrm{Fe}^{2+}$ was determined by measuring absorbance of the Perl's Prussian blue complex. This method is based on the reduction of $\left(\mathrm{Fe}^{3+}\right)$ ferricyanide in stoichiometric excess $(0.1$, 0.2 , and $0.4 \mathrm{mg} / \mathrm{ml}$ ) of water, methanol, ethyl acetate and hexane extracts of sumac $S$. undulata in $0.75 \mathrm{ml}$ of distilled water were mixed with $1 \mathrm{ml}$ of $0.2 \mathrm{M}$ sodium phosphate buffer ( $\mathrm{pH} \mathrm{6.6)}$ and $1 \mathrm{ml}(1 \%)$ of potassium ferricyanide $\left[\mathrm{K}_{3} \mathrm{Fe}(\mathrm{CN})_{6}\right]$. The mixture was incubated at $50^{\circ} \mathrm{C}$ for $20 \mathrm{~min}$. After $20 \mathrm{~min}$ of incubation, the reaction mixture was acidified with $1 \mathrm{ml}$ of trichloroacetic acid (10\%). Finally, $0.25 \mathrm{ml}$ of $\mathrm{FeCl}_{3}(0.1 \%)$ was added to this solution. Distilled water was used as blank and for control. Absorbance of this mixture was measured at $700 \mathrm{~nm}$ using a UV spectrophotometer. Decreased absorbance indicates ferric reducing power capability of sample. Ascorbic acid and Butylated hydroxytoluene (BHT) were used for comparison.

\section{Optimization of phenolic content extraction}

The influence of solvent, maceration period, temperature and agitation on phenolic extraction was evaluated using a full factorial design $\left(2^{4}\right)$ with three replicates in the central points, which was a total of 16 treatment combinations. In the statistical model, the coded variables were defined as follows: $X 1=$ solvent, $X 2=$ maceration period, $X 3=$ temperature, $X 4=$ agitation and the dependent variables being phycocyanin concentration. Each independent variable was coded at two levels between -1 (low level) and +1 (high level). The coding of the variables was done by the following:

$$
x i=(X i-X z) / \Delta X i, i=1,2,3, \ldots, k
$$

where:

$x i$ - the dimensionless value of an independent variable,

$X i$ - the real value of an independent variable,

$X z$ - the real value of an independent variable at the center point, 

oxidant properties of Scorzonera undulata (Asteraceae): Application of factorial design optimization phenolic extraction. Acta Sci. Pol. Technol. Aliment., 14(4), 313-330. DOI: 10.17306/J.AFS.2015.4.32

$\Delta X i$ - the step change of the real value of the variable $i$ corresponding to a variation of a unit for the dimensionless value of the variable $i$.

The levels of each factor are listed in Table 1. Table 2 presents the experimental design matrix.

Table 1. Factor levels for a $2^{4}$ factorial design

\begin{tabular}{clcc}
\hline \multirow{2}{*}{ Factors } & \multicolumn{1}{c}{ Parameters } & \multicolumn{2}{c}{ Coded level } \\
\cline { 3 - 4 } & & -1 & +1 \\
\hline$X 1$ & Solvent (methanol), \% & 80 & 100 \\
$X 2$ & Maceration, h & 24 & 48 \\
$X 3$ & Temperature, ${ }^{\circ} \mathrm{C}$ & 25 & 35 \\
$X 4$ & Agitation, rpm & 20 & 50 \\
\hline
\end{tabular}

Table 2. Factorial design matrix with experimental results and actual values for phenolic content extraction

\begin{tabular}{cccccc}
\hline & \multicolumn{3}{c}{ Factors } & \multicolumn{2}{c}{ Polyphenol content } \\
\cline { 2 - 6 } & $X 1$ & $X 2$ & $X 3$ & $X 4$ & Actual value \\
\hline 1 & -1 & -1 & -1 & -1 & 3.14 \\
2 & +1 & -1 & -1 & -1 & 3.42 \\
3 & -1 & +1 & -1 & -1 & 3.25 \\
4 & +1 & +1 & -1 & -1 & 6.07 \\
+1 & -1 & -1 & +1 & -1 & 2.87 \\
+1 & +1 & -1 & +1 & -1 & 3.17 \\
+1 & -1 & +1 & +1 & -1 & 4.26 \\
+1 & +1 & +1 & +1 & -1 & 4.08 \\
+1 & -1 & -1 & -1 & +1 & 4.57 \\
+1 & +1 & -1 & -1 & +1 & 4.83 \\
+1 & -1 & +1 & -1 & +1 & 7.64 \\
+1 & -1 & +1 & -1 & +1 & 6.21 \\
+1 & -1 & -1 & +1 & +1 & 4.23 \\
+1 & +1 & -1 & +1 & +1 & 2.81 \\
+1 & -1 & +1 & +1 & +1 & 7.11 \\
+1 & +1 & +1 & +1 & +1 & 5.06 \\
\hline
\end{tabular}

\section{Statistical analysis of data}

All experiments were repeated twice and carried out in a completely randomized block design; each treatment consisted of three replicates. Mean values of various treatments were subjected to analysis of variance (ANOVA) using IBM SPSS Statistics version 20 Significance level was determined (at $p<0.05$ ) and significant difference was separated using Duncan's Multiple Range Test (DMRT). Pearson's rank-correlation was performed using XL-Stat software to determine the correlations between the phenolic compounds and the antioxidant activity in the different extracts of S. undulata.

\section{RESULTS AND DISCUSSION}

\section{Phytochemical screening}

Previous studies indicated that different solvents could lead to different extraction efficiencies of bioactive compounds (Vuong et al., 2013; Zhang et al., 2013). Therefore, this study determined the impact of four different extraction solvents with various polarity indexes to identify the most effective solvent for further optimization using response surface methodology. According to our knowledge, the chemical analysis of phenolic content, flavonoids, anthocyanins and condensed tannins of $S$. undulata from a Tunisian arid area has not yet been investigated.

\section{Total phenolic content in different extracts (TPC).} Polyphenols have attracted considerable attention because of their various biological activities including: antioxidant, antimutagenic, antitumor, anti-inflammatory, neuro-protective and cardio-protective effects (Tai et al., 2011). Phenolic compounds are health benefactors because they act as antioxidative agents (Oztürk et al., 2011). The total phenolic contents (TPC) in $S$. undulata roots have been evaluated. The quantitative determination of TPC is expressed as milligram gallic acid equivalents per gram dry weight of sample. In the present study, the total phenolic contents of n-hexane, ethyl acetate, methanol and aqueous extracts of S. Scorzonera roots were determined by the Folin-Ciocalteu method and results are shown in Table 3. The methanol extract of the roots exhibited the highest content (6.12 $\pm 0.11 \mathrm{mg}$ EAG/g DW) followed by the n-Hexan fraction $(5.95 \pm 0.01 \mathrm{mg}$ EAG/g DW). It is reported 
Athmouni, K., Belghith, T., Bellassouad, K., El Feki, A., Ayadi, H. (2015). Effect of extraction solvents on the biomolecules and antioxidant properties of Scorzonera undulata (Asteraceae): Application of factorial design optimization phenolic extraction. Acta Sci. Pol. Technol. Aliment., 14(4), 313-330. DOI: 10.17306/J.AFS.2015.4.32

Table 3. Effects of extracts of Scorzonera undulata on the in vitro free radical (DPPH, FRAP, ABTS and reducing power)

\begin{tabular}{lccccc}
\hline & \multicolumn{3}{c}{ Antioxydant activity } \\
\cline { 2 - 6 } \multicolumn{1}{c}{ Extracts } & $\begin{array}{c}\text { DPPH } \\
\%\end{array}$ & $\begin{array}{c}\mathrm{IC}_{50} \\
\mathrm{mg} / \mathrm{ml}\end{array}$ & $\begin{array}{c}\text { FRAP } \\
\text { Mm TE/g DW }\end{array}$ & $\begin{array}{c}\text { ABTS }^{\circ} \\
\text { Mm TE/g DW }\end{array}$ & $\begin{array}{c}\text { Reducing power } \\
(700 \mathrm{~nm})\end{array}$ \\
\hline Ethyl acetate $(0.4 \mathrm{mg} / \mathrm{ml})$ & $67.16^{\mathrm{b}}$ & $0.21 \pm 0.06^{\mathrm{e}}$ & $0.16 \pm 0.001^{\mathrm{a}}$ & $0.8 \pm 0.11^{\mathrm{b}}$ & $0.871^{\mathrm{d}}$ \\
Methanol $(0.4 \mathrm{mg} / \mathrm{ml})$ & $83.42^{\mathrm{cd}}$ & $0.14 \pm 0.02^{\mathrm{c}}$ & $0.31 \pm 0.002^{\mathrm{a}}$ & $1.36 \pm 0.07^{\mathrm{b}}$ & $0.776^{\mathrm{b}}$ \\
n-Hexane $(0.4 \mathrm{mg} / \mathrm{ml})$ & $72.24^{\mathrm{bc}}$ & $0.17 \pm 0.04^{\mathrm{d}}$ & $0.005 \pm 0.00^{\mathrm{a}}$ & $1.01 \pm 0.04^{\mathrm{b}}$ & $0.830^{\mathrm{c}}$ \\
Water $(0.4 \mathrm{mg} / \mathrm{ml})$ & $61.31^{\mathrm{a}}$ & $0.31 \pm 0.01^{\mathrm{f}}$ & $0.045 \pm 0.002^{\mathrm{a}}$ & $0.12 \pm 0.03^{\mathrm{a}}$ & $0.574^{\mathrm{a}}$ \\
BHT $(0.4 \mathrm{mg} / \mathrm{ml})$ & $93.12^{\mathrm{d}}$ & $0.12 \pm 0.03^{\mathrm{b}}$ & $1.85 \pm 0.02^{\mathrm{b}}$ & $1.75 \pm 0.04^{\mathrm{c}}$ & $0.957^{\mathrm{e}}$ \\
Vit. C $(0.4 \mathrm{mg} / \mathrm{ml})$ & $96.32^{\mathrm{d}}$ & $0.10 \pm 0.02^{\mathrm{a}}$ & $1.96 \pm 0.01^{\mathrm{b}}$ & $1.91 \pm 0.012^{\mathrm{c}}$ & $0.996^{\mathrm{f}}$ \\
\hline
\end{tabular}

Data are presented as mean $\pm \mathrm{SD}$ of three individual determinations. GAE - gallic acid equivalents. $\mathrm{CE}$ - catechin equivalents. TE - the trolox equivalent. DW - dry weight. Values followed by different superscript in each column are significantly different $(P<0.05)$.

$\mathrm{IC}_{50}-$ concentration of sample required to scavenge $50 \%$ of free radicals.

by other researchers (Sun et al., 2011) that methanol was an effective solvent for extracting phenolic compounds. Milella et al. (2014) indicated that total phenolic content of methanol/water extract of $S$. undulata roots is about $80.7 \mathrm{mg} \mathrm{GAE} / \mathrm{g}$ of extract, which seems to be more important than the results obtained in the present study. According to Shahat et al. (2014), the total phenolic content of six species of Asteraceae family (Picris cyanocarpa, Pulicaria crispa, Anthemis deserti, Achillia fragrantissima, Rhantarium appoposum and Artemissia monosperma) ranged from 0.01 to $0.055 \mathrm{mg} \mathrm{GAE} / \mathrm{g}$ DW, with Artemissia monosperma showing the highest value of $0.055 \mathrm{mg} \mathrm{GAE} / \mathrm{g} \mathrm{DW}$, followed by Picris cyanocarpa, Pulicaria crispa, Anthemis deserti, Rhantarium appoposum and Achillia fragrantissima with TPC values of $0.038,0.035,0.028$, 0.01 and $0.009 \mathrm{mg} \mathrm{GAE} / \mathrm{g} \mathrm{DW}$, respectively. In addition, several studies revealed that phenolic compounds content differed with solvents polarities (Addai et al., 2013; Fernandez-Arroyo et al., 2011). Turkmen et al. (2006) reported that solvent with different polarity had significant effect on phenolics compound and antioxidant activity in highest content in most polar solvents. This finding could be the result of non specific reactions of Folin-Ciocalteu reagent with other components of the water extract which could overestimate the phenolic content in these extracts (Galher et al., 2003). In addition, it is difficult to compare our results with historical data. Indeed, the extraction of phenolic compounds from their natural matrix is complicated by their diversity and their susceptibility to oxidation and hydrolysis (Naczk and Shahidi, 2004). Concerning the ethyl acetate and water fractions, they are less enriched in total phenolic compounds $(3.5 \pm 0.06$ and $0.94 \pm 0.05 \mathrm{mg} \mathrm{EAG} / \mathrm{g}$ DW respectively). Methanol, hexane, ethyl acetate and aqueous extracts of $S$. undulata roots showed significant difference $(* * * p<$ 0.001 ) in total phenolic content. We can conclude that ethyl acetate and methanol extracts had the highest total phenolic contents. In fact, the use of solvents with different polarities leads to differences in phenolic content and antioxidant capacity (Matthäus et al., 2002; Gorinstein et al., 2007). In this regard, several authors have remarked the importance of the extraction method and the solvent used (Gorinstein et al., 2007; Nsimba et al., 2008; Ozsoy et al., 2009). In addition, in plant preparations (extracts, decoctions), the content and composition of antioxidants depend also on extraction technique, its conditions (extraction time and temperature), and solvents (Škrovánková et al., 2012).

Determination of total flavonoids content. Flavonoids (phenolic plant compounds) possess a wide range of pharmacological properties. Its importance to human health lies in its capacity to scavenge free 

oxidant properties of Scorzonera undulata (Asteraceae): Application of factorial design optimization phenolic extraction. Acta Sci. Pol. Technol. Aliment., 14(4), 313-330. DOI: 10.17306/J.AFS.2015.4.32

radicals (Robards et al., 1999). In the present investigation, the aluminum chloride colorimetric method was used for detection of flavonoids content, which increased from water to ethyl acetate fractions. In this study the ethyl acetate extract presents the highest flavonoids content $(2.90 \pm 0.05 \mathrm{mg} \mathrm{CE} / \mathrm{g} \mathrm{DW})$ followed by the n-hexanoic fraction $(2.41 \pm 0.14 \mathrm{mg} \mathrm{CE} / \mathrm{g} \mathrm{DW})$. Water and methanolic fractions showed the lowest flavonoids content $(1.62 \pm 0.04$ and $2.30 \pm 0.15 \mathrm{mg} \mathrm{CE} / \mathrm{g}$ DW, respectively). Methanol, n-hexane, ethyl acetate and aqueous extracts of $S$. undulata showed significant difference $(* * * p<0.001)$ in flavonoids content. According to Erden et al. (2013), the total flavonoids content of three Scorzonera species extracted with methanol solvent: Scorzonera suberosa $(0.26 \pm 0.05$ $\mathrm{mg} / \mathrm{g}$ DW), Scorzonera laciniata $(0.08 \pm 0.01)$ and Scorzonera latifolia $(0.17 \pm 0.01 \mathrm{mg} / \mathrm{g} \mathrm{DW})$, these results are less important than those revealed by the present study. Moreover, Gouveia et al. (2013) indicated that the flavonoids content of the ethanol extract of Andryala glandulosa (Asteraceae family) is about $3.28 \pm 0.01 \mathrm{mg} \mathrm{RE} / \mathrm{g}$ DW. In comparison to the present study, the findings of the previous studies dealing with Scorzonera species are less important. In fact, the increase or decrease of flavonoids content depended on the extraction solvent polarity (Hsu et al., 2006; Segura-Carretero and Fernandez-Gutierrez, 2013).

Determination of anthocyanins content. Anthocyanidin, an important plant pigment, is responsible for most of the purple, red and blue colours in plants. It is a flavonoid compound synthesized from phenylalanine and malonylcoa through a series of enzymatic reactions (Holton and Cornish, 1995; Chopra el al., 1996; Mol et al., 1998). It has been known that anthocyanins possess antitumor, antiulcer and anti-inflammatory properties (Konczak-Islam, 2003; Kong et al., 2003; Hou et al., 2004; Stintzing and Carle, 2004). In the present study, the anthocyanins content of methanol, n-hexane, ethyl acetate and water extracts of $S$. undulata roots was determined by the $\mathrm{pH}$ differential method and results are shown in Figure 2. The ethyl acetate extract of $S$. undulata presented the highest anthocyanins content $(28.56 \pm 3.96 \mathrm{mg} / \mathrm{kg} \mathrm{DW})$ followed

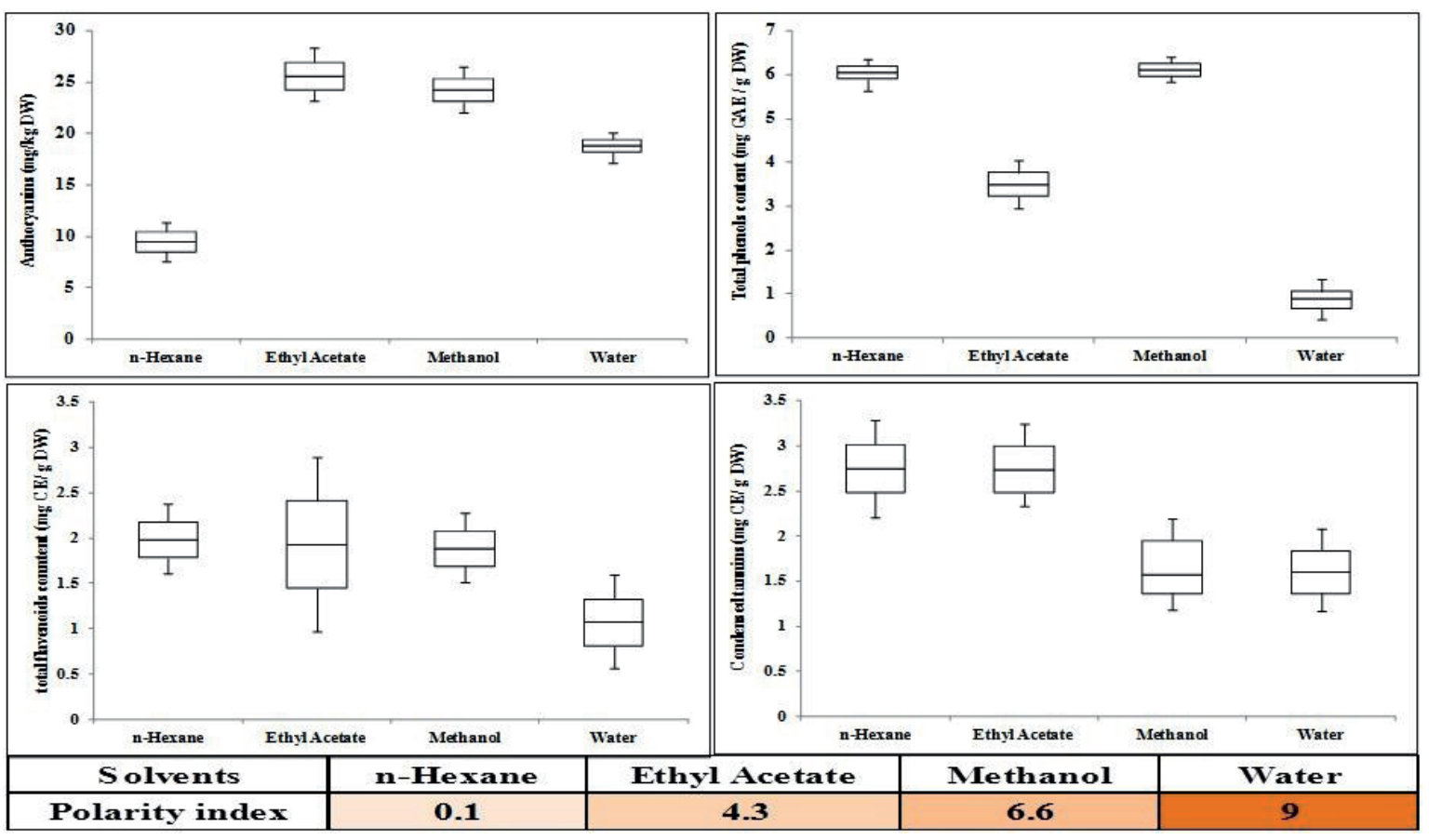

Fig. 2. Total phenol, flavonoids, anthocyanins content and condensed tannins content of Scorzonera undulata extracts 
Athmouni, K., Belghith, T., Bellassouad, K., El Feki, A., Ayadi, H. (2015). Effect of extraction solvents on the biomolecules and antioxidant properties of Scorzonera undulata (Asteraceae): Application of factorial design optimization phenolic extraction. Acta Sci. Pol. Technol. Aliment., 14(4), 313-330. DOI: 10.17306/J.AFS.2015.4.32

by the methanolic fraction $(26.25 \pm 3.15 \mathrm{mg} / \mathrm{kg} \mathrm{DW})$. The least concentration of anthocyanins was observed in n-hexanoic fraction $(11.85 \pm 2.72 \mathrm{mg} / \mathrm{kg} \mathrm{DW})$ followed by aqueous fraction $(17.54 \pm 1.80 \mathrm{mg} / \mathrm{kg} \mathrm{DW})$. Methanol, n-hexane, ethyl acetate and aqueous extracts of $S$. undulata showed significant difference $(* * * p 0.001)$ in of anthocyanins content. In comparison with other materials belonging to the Asteraceae family (Artemisia herba-alba, Ruta chalpensis and $\mathrm{Pe}$ ganum hamala) extracted with methanol/water (3/1), the anthocyanins content ranged from $176.99 \pm 5.05$ to $1949 \pm 2$ mg/kg DW, with Artemisia herba-alba, Ruta showing the highest value of $1949 \pm 2 \mathrm{mg} / \mathrm{kg}$ DW, followed by Ruta chalpensis and Peganum hamala with anthocyanins content values of $413.29 \pm 3.46$ and 176 $\pm 5.05 \mathrm{mg} / \mathrm{kg} \mathrm{DW}$, respectively (Khlifi et al., 2013). In fact, anthocyanins are polar molecules which are normally extracted from raw plant tissues by conventional solvent extraction (CSE) methodologies, using polar solvents. However, the type of matrix and solvent used plays an important role for the extraction of anthocyanins (Ramos-Escudero et al., 2012).

Determination of condensed tannins. Many tannin-rich medicinal and food plants have been appreciated for their beneficial effects without being troubled by any obvious toxicity (Okuda, 1999). Research on the tannins in traditional medicinal plants, presented here, started when the chemical, biological and pharmacological properties of tannins in most medicinal plants were not yet subjected to modern analysis (Okuda et al., 1975; 1991; 1992; 1995). In the present study, the tannins content of methanol, n-hexane, ethyl acetate and aqueous extracts of $S$. undulata were determined by the vanillin method and results are presented in Figure 2. The highest level of tannins content was measured in the ethyl acetate extract $(3.25 \pm 0.06$ $\mathrm{mg} \mathrm{CE} / \mathrm{g} \mathrm{DW}$ ) followed by the n-hexane extract (2.21 $\pm 0.26 \mathrm{mg} \mathrm{CE} / \mathrm{g} \mathrm{DW}$ ). Methanol extract of $S$. undulata and aqueous fraction showed low tannins content compared to ethyl acetate extract ( $2.12 \pm 0.05$ and 1.17 $\pm 0.02 \mathrm{mg} \mathrm{CE} / \mathrm{g} \mathrm{DW}$, respectively). The different extracts of $S$. undulata showed a significant difference $\left({ }^{* * *} p<0.001\right)$ in condensed tannins amounts. In comparison with other materials, these extracts contained lower condensed tannin than those obtained from $\mathrm{Ar}$ temisia herba-alba (5.47 $\pm 0.09 \mathrm{mg} \mathrm{CE} / \mathrm{g} \mathrm{DW})$, Ruta chalpensis (4.73 $\pm 0.14 \mathrm{mg} \mathrm{CE} / \mathrm{g} \mathrm{DW})$ and Peganum hamala (2.03 $\pm 0.06 \mathrm{mg} \mathrm{CE} / \mathrm{g} \mathrm{DW})$ (Khlifi et al., 2013). Generally, the extraction efficiency of bioactive compounds is largely depending on the solvent used (Leblanc et al., 2009; Xi et al., 2009; Chen et al., 2012). The present study shows that among all the solvent; ethyl acetate and water were better solvents for effective extraction of tannins as compared to other solvents like n-hexane and methanol. According to (Mailoa et al., 2013), the polar-aprotic solvent cannot provide $\mathrm{OH}$-ions, whereas the polar protic solvent can provide $\mathrm{OH}$-ions, making it easier to interact with polar functional groups on the tannins. Therefore, the polar-aprotic solvents are less compatible to tannins extraction than polar-protic solvent (e.g. ethanol).

\section{Antioxidant activity of $S$. undulata extracts}

Extraction of active compounds in natural plants is potent to protect biological systems against damaging effect of natural oxidation process in organism. In this study, the antioxidant capacity of $S$. undulata using different extracting solvent was evaluate by 4 assays; $\mathrm{DPPH}, \mathrm{FRAP}, \mathrm{ABTS}^{+\bullet}$ and Reducing power. Each antioxidant assay possesses its own unique mechanism to evaluate the antioxidant activity in sample.

DPPH radical scavenging activity. The antioxidant potential of methanol, $n$-hexane and aqueous extracts of $S$. undulata was evaluated on the basis of their ability to scavenge stable free DPPH radicals and results, while the $\mathrm{IC}_{50}$ values were presented in Table 3 . This test is based on change in colour of DPPH solution from purple to yellow, due to scavenging of stable free DPPH radicals (Khadri et al., 2010). A stronger yellow colour indicates a greater ability of the extract to scavenge free DPPH radicals and stronger antioxidant potential. The strongest scavenging activity was observed in methanolic fraction followed by n-hexane extract, with $\mathrm{IC}_{50}$ values of $0.14 \pm 0.02$ and $0.17 \pm 0.04$ $\mathrm{mg} / \mathrm{ml}$ of extract respectively. The ethyl acetate and water extracts of $S$. undulata roots have the lowest $\mathrm{DPPH}^{\circ}$ radical scavenging ability over other extracts, with $\mathrm{IC}_{50}$ values of $0.21 \pm 0.06$ to $0.31 \pm 0.01 \mathrm{mg} / \mathrm{ml}$ of extract respectively. ANOVA test shows a significant difference between the used extracts $(* * * p<0.001)$ in DPPH scavenging assay. The highest antioxidant activity in methanol fraction could be related to the 

oxidant properties of Scorzonera undulata (Asteraceae): Application of factorial design optimization phenolic extraction. Acta Sci. Pol. Technol. Aliment., 14(4), 313-330. DOI: 10.17306/J.AFS.2015.4.32

high phenolic compounds content showed by this extract. Amoateng et al. (2011) reported that DPPH scavenging ability of Synedra nodiflora (Asteraceae family) extracted in ethanol solvent $(70 \%)$ is about $0.31 \mathrm{mg} / \mathrm{ml}$ of extract, suggesting that our results are more important. In the $\mathrm{DPPH}^{\bullet}$ assay, the free radical scavenging activities decreased from methanol extract to n-hexanoic, ethyl acetate and aqueous extracts for $S$. undulata roots evidencing a clear secondary metabolite content due to the solvent-solvent partitioning processes (Lixiang et al., 2009). An increase in DPPH scavenging ability was observed with increase in concentration of extracts. In comparison with other genus belonging to the Asteraceae family, Kenny et al. (2014) reported that the $\mathrm{DPPH} \mathrm{IC}_{50}$ of Circum arvence, Circum vulgare, Circum polusture, Circum nigra, Circum scabiosa, Circum asper, Articulum minus and Taraxacum officinale extracted with water was $0.48 \pm 0.04,2.23 \pm 0.12,0.81 \pm 0.05,0.58 \pm 0.03,0.78$ $\pm 0.009,1.92 \pm 0.25,2.45 \pm 0.19$ and $0.48 \pm 0.006 \mathrm{mg} / 1$ of extract respectively, which is close to the results obtained by the present study. The DPPH radical was widely used to evaluate the free-radical scavenging capacity of antioxidants (Cotelle et al., 1996). We can conclude that the ethyl acetate extract was the most effective in this respect.

FRAP analysis. FRAP method was used to present rather quick and simple method measuring antioxidant presents in S. scorzonera roots. The FRAP assay is based on the ability of phenolics to reduce yellow ferric tripyridyltriazine complex (Fe(III)-TPTZ) to blue ferrous complex (FE(II)-TPTZ) by the action of electron donating antioxidants (Benzie and Stain, 1996). In the present study, antioxidant activities evaluated by the FRAP scavenging capacity of methanol, ethyl acetate, hexanoic and water extracts of the samples are presented in Table 3. The roots of $S$. undulata showed higher antioxidant activity in methanol extract $(0.31$ $\pm 0.002 \mathrm{mg}$ TE$/ \mathrm{g} \mathrm{DW}$ ) followed by ethyl acetate fraction $(0.16 \pm 0.001 \mathrm{mg}$ TE/g DW). In comparison with other genus belonging to the Asteraceae family, Wojdyło et al. (2007) reported that the FRAP scavenging of Achillea millefolium and Echinacea purpurea extracted with methanol was 0.47 and $0.22 \mathrm{mg} \mathrm{TE} / \mathrm{g}$ DW respectively, which is very low compared to the results obtained by the present study. The least amount of FRAP scavenging was observed in water extract $(0.045 \pm 0.002 \mathrm{mg}$ TE/g DW) followed by hexanoic fraction $(0.005 \pm 0.00 \mathrm{mg}$ TE/g DW). In FRAP assay, the scavenging activities decreased from methanol to n-hexane extract in $S$. undulata roots, thus, the polarity of solvents has an indirect function in the extraction process, because it can raise the solubility of antioxidant compounds (Alothman et al., 2009).

ABTS $^{++}$scavenging activity. ABTS assay is based on the antioxidant ability of the extracts to react with $\mathrm{ABTS}^{+}$radical cation generated in the system. The averages values obtained for ABTS assay are given in Table 3. ABTS (blue-green chromophore) is mixed with the different extracts of $S$. undulata that can donate a hydrogen atom, then this gives rise to the reduced form with the loss of their color (Molyneux, 2004). Solvent used for phenolic compounds extraction had a significant effect on antioxidant activity. The highest level of scavenging activity was measured in the methanol extract $(1.36 \pm 0.07 \mathrm{Mm}$ TE/g DW) followed by the $\mathrm{n}$-hexane fraction is about $1.01 \pm 0.04 \mathrm{Mm} \mathrm{TE} / \mathrm{g}$ DW. Similarly, in another investigation by Sultana et al. (2007), methanol extract was found to be the solvent extracting the most efficiently antioxidants. Ethyl acetate and aqueous fractions have moderate activity $(0.8$ \pm 0.11 and $0.12 \pm 0.03 \mathrm{Mm} \mathrm{ET/g} \mathrm{DW,} \mathrm{respectively).} \mathrm{The}$ scavenging effect of different extracts of $S$. undulata on the $\mathrm{ABTS}^{+}$radical decreased in following order: ascorbic acid $>$ BHT $>$ methanol $>$ n-hexane $>$ ethyl acetate $>$ water extracts. In comparison with another study, the ABTS activity of Artemisia capillaris is about 0.27 $\pm 0.02 \mathrm{Mm}$ TE/g DW, Artemisia argyi $(0.24 \pm 0.007 \mathrm{Mm}$ TE/g DW) and Artemisia apiacea (0.05 $\pm 0.002 \mathrm{Mm}$ TE/g DW) (Li et al., 2013), which is much lower than the results obtained in the present study.

Reducing power. In the present study, the reducing power of chemical compounds extracted from S. undulata roots by methanol, hexane, ethyl acetate and water was determined and shown in Table 3 . The reducing power of extracts and standard antioxidants decreased in the order of vit. $\mathrm{C}>\mathrm{BHT}>$ ethyl acetate extract $>$ n-hexane $>$ methanol $>$ aqueous extracts, in presence of $0.4 \mathrm{mg} / \mathrm{ml}$ test sample (Fig. 3). According to the results obtained in the present study, both ferric reducing power and total phenolic content of ethyl 


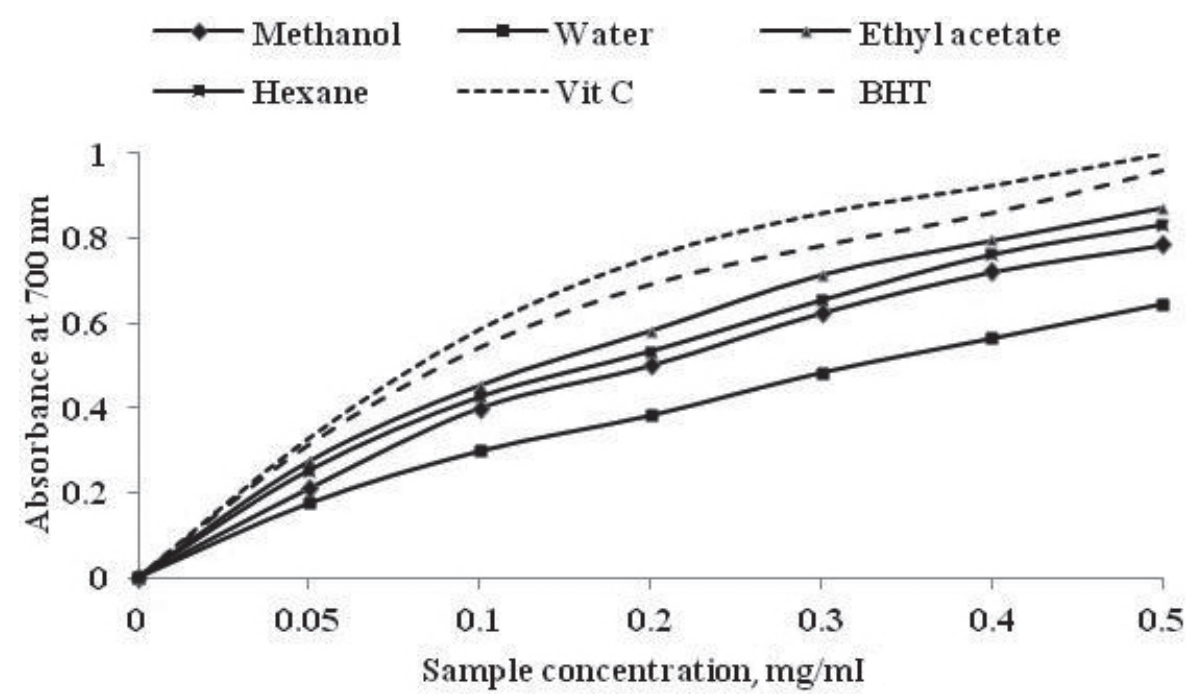

Fig. 3. Reducing power of methanol, ethyl acetate, hexane and water extracts of Scorzonera undulata

acetate extract were higher than those of the hexane extract. Significant difference $(* * * p<0.001)$ in reducing power activity was noted in all of the investigated extracts. Total phenolic content and ferric reducing power are related with each other. Fe (III) reduction is often used as an indicator of electron-donating activity, which is an important mechanism of phenolic antioxidant action (Dorman et al., 2003). According to Shahat et al. (2014) at $0.4 \mathrm{mg} / \mathrm{ml}$, the absorbance values of methanolic extract, at $700 \mathrm{~nm}$ were $0.2 ; 0.2$; $0.27 ; 0.23 ; 0.19$ and 0.22 , respectively in dry sample from P. Crupa, R. Epapposum, P. Cyanocarpa, A. Deserti, A. Fragrantissima and A. monosperma. Compared to the present study, these plants reveal an antioxidant activity less important than $S$. undulata.

\section{Correlation between phenolic compounds and antioxidant activity}

Several studies have reported on the relationship between total phenol and antioxidant activity. Some authors have found a strong correlation between the phenolic contents and the antioxidant activity (Ramful et al., 2011; Ouchemoukhe et al., 2012; Benmeddour et al., 2013) others have found nothing (Amin et al., 2004; Anagnostopoulou et al., 2006; Kamran et al., 2009). In this study, the results have shown a relationship between antioxidant activity and total phenolic contents. Table 4 showed the Pearson's rankcorrelation between the antioxidant activity and the phytochemical composition of the different extracts. The findings of this study indicate that total phenolics present high and positive correlations with ABTS scavenging capacity and DPPH $(r=0.990, p<0.05$ and $r=0.965, p<0.05$, respectively). While a high and positive correlation was obtained between flavonoids and the reducing power $(r=0.861, p<0.05)$. In fact, it is known that only flavonoids with a certain structure and particularly hydroxyl position in the molecule can act as proton donating and show radical scavenging activity (Hou et al., 2003). Furthermore, the extracts are very complex mixtures of many different compounds with distinct activities (Hou et al., 2003). Anthocyanins are strongly correlated with FRAP $(r=0.737$, $p<0.05)$. Contrary to the condensed tannins that have shown only a correlation with the reducing power $(r=0.807, p<0.05)$. A principal component analysis (PCA) was performed in order to visualize the correlations that might exist between the phytochemical composition and the antioxidant activity. Figure 4 shows two groups: the first group (G1) is correlated with the ethyl acetate extract and contains the following parameters: anthocyanins, condensed tannins, flavonoids and the reducing power. The second group shows a correlation between the methanolic extract, the FRAP radical 
Athmouni, K., Belghith, T., Bellassouad, K., El Feki, A., Ayadi, H. (2015). Effect of extraction solvents on the biomolecules and antioxidant properties of Scorzonera undulata (Asteraceae): Application of factorial design optimization phenolic extraction. Acta Sci. Pol. Technol. Aliment., 14(4), 313-330. DOI: 10.17306/J.AFS.2015.4.32

Table 4. Pearson's correlation coefficients $(r)$ of the phenolic compounds and the antioxidant activities

\begin{tabular}{|c|c|c|c|c|c|c|c|c|}
\hline & $\begin{array}{c}\text { Total } \\
\text { phenolic }\end{array}$ & Flavonoids & $\begin{array}{c}\text { Condensed } \\
\text { tannins }\end{array}$ & $\begin{array}{l}\text { Anthocya- } \\
\text { nins }\end{array}$ & $\begin{array}{c}\text { DPPH } \\
\text { scavenging }\end{array}$ & ABTS & FRAP & $\begin{array}{c}\text { Reducing } \\
\text { power }\end{array}$ \\
\hline Total phenolic & 1 & & & & & & & \\
\hline Flavonoids & 0.180 & 1 & & & & & & \\
\hline Condensed tannins & 0.103 & $0.994^{*}$ & 1 & & & & & \\
\hline Anthocyanins & 0.126 & $0.534^{*}$ & $0.596^{*}$ & 1 & & & & \\
\hline DPPH scavenging & $0.965^{*}$ & -0.014 & -0.075 & 0.176 & 1 & & & \\
\hline ABTS & $0.990^{*}$ & 0.307 & 0.236 & 0.231 & $\mathbf{0 . 9 3 8}^{*}$ & 1 & & \\
\hline FRAP & $0.592^{*}$ & 0.071 & 0.090 & $0.737^{*}$ & $0.724^{*}$ & $0.618^{*}$ & 1 & \\
\hline Reducing power & $0.639^{*}$ & $0.861^{*}$ & $0.807^{*}$ & 0.363 & 0.448 & $0.726^{*}$ & 0.245 & 1 \\
\hline
\end{tabular}

${ }^{*} p<0.05$.

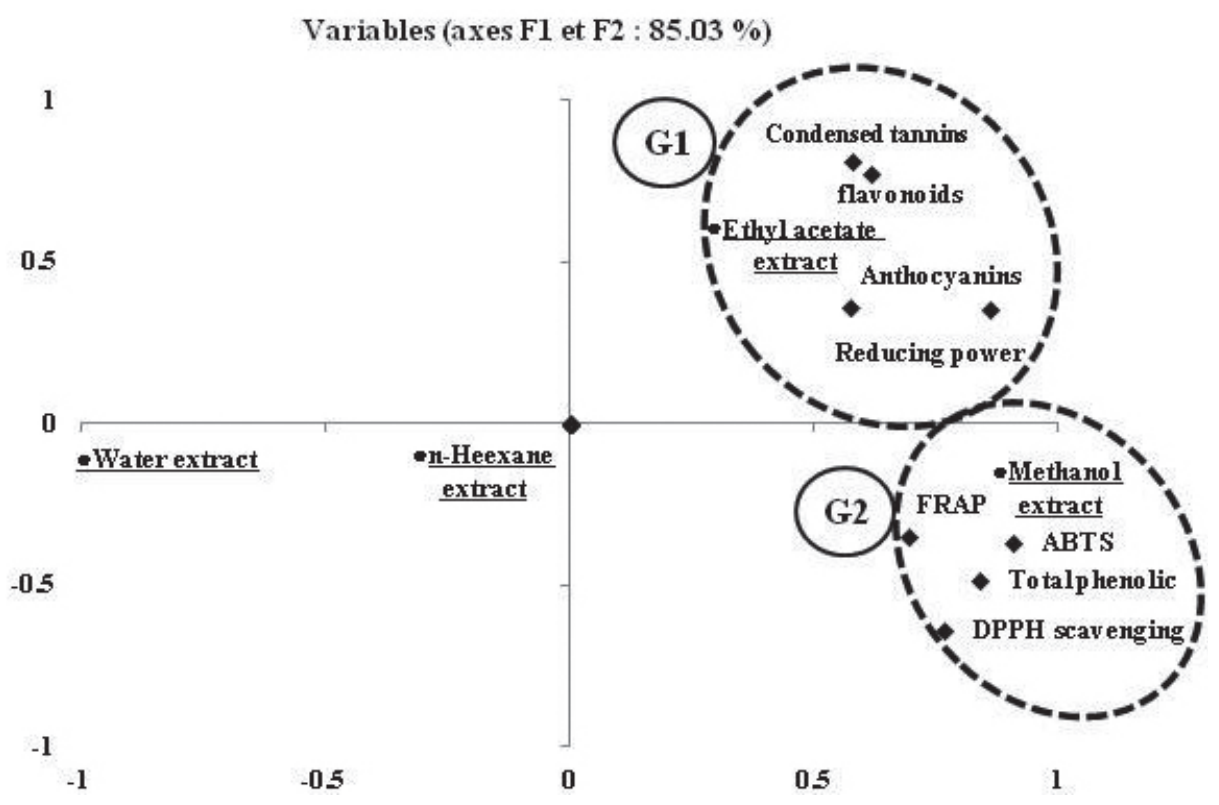

Fig. 4. Principal Component Analysis (PCA) of the biomolecule and antioxidant activity

scavenging, the ABTS scavenging ability, the DPPH scavenging activity and the total phenolic content.

\section{Optimization of polyphenol extraction}

Since the model initially contains significant and non significant terms, it can be adjusted by eliminating the non-significant terms. Leon and Kumar (2007) suggested that full quadratic models should be used even if some terms are insignificant, because certain statistical properties are valid only in the full quadratic case. Myers et al. (2009) argue that reduced models containing only significant terms should be employed, especially when the goal is to find the optimal settings of major factors. The Pareto chart in Figure 5 shows all of the parameter effects and their interactions in decreasing order of importance. This figure uses a vertical line to 


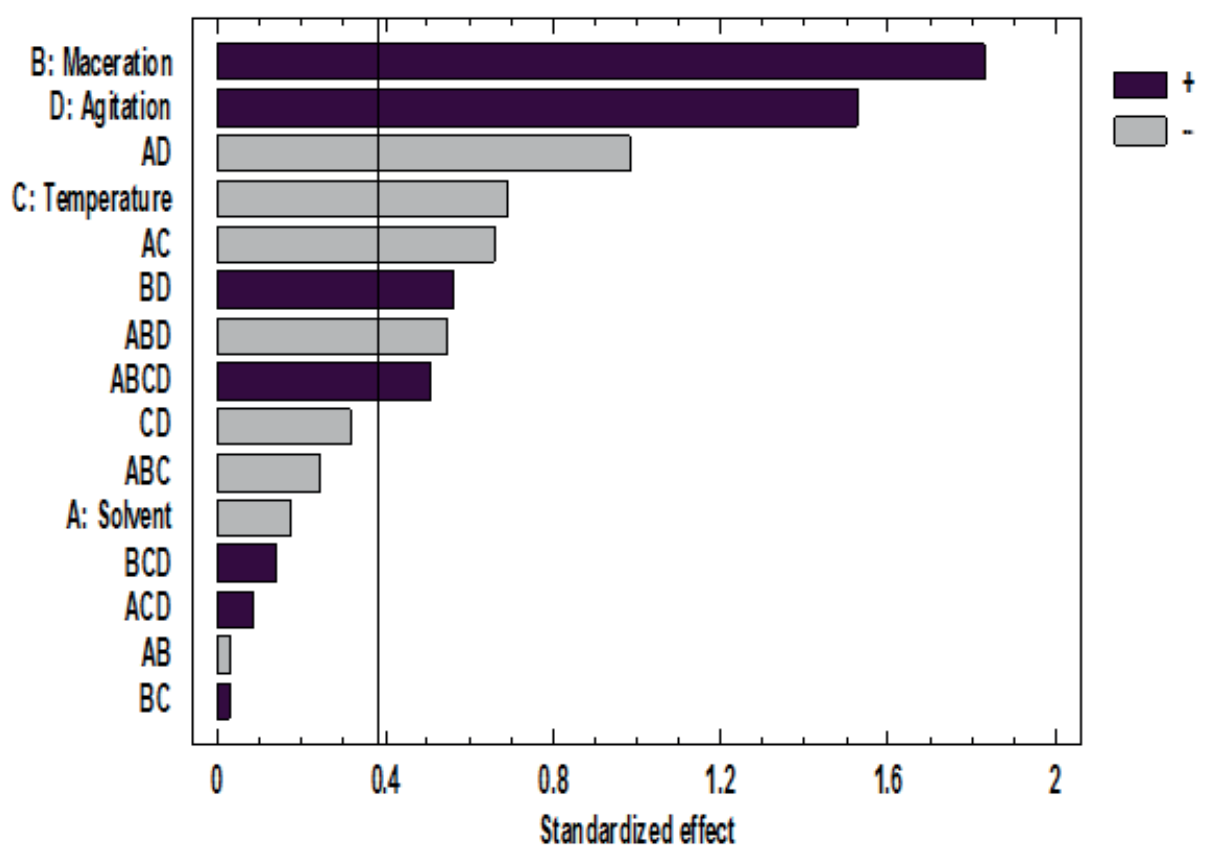

Fig. 5. Standardized Pareto chart for efficiency

determine which effects are statistically significant. The length of each bar is proportional to the value of the statistics calculated for the associated effect. Any bars beyond the vertical line are statistically significant at the selected level of significance. The (+) sign indicates a positive contribution of the effect, while the (-) sign indicates a negative contribution. In the present case, there are four main effects (A: Solvent, B: Maceration,
C: Temperature and D: Agitation) and four significant interactions ( $\mathrm{AD}, \mathrm{AC}, \mathrm{AB}, \mathrm{ABD}$ and $\mathrm{ABCD})$. The values given in Figure 5 indicate that the effect of whole diameter (parameter $\mathrm{A}$ ) is not significant and that all interactions involving this parameter $(\mathrm{AB} ; \mathrm{BC}$ and $\mathrm{BCD})$ are negligible. In addition, the main effects plot depicted in Figure 6 shows the estimated change in efficiency of the phenolic content when each of the factors

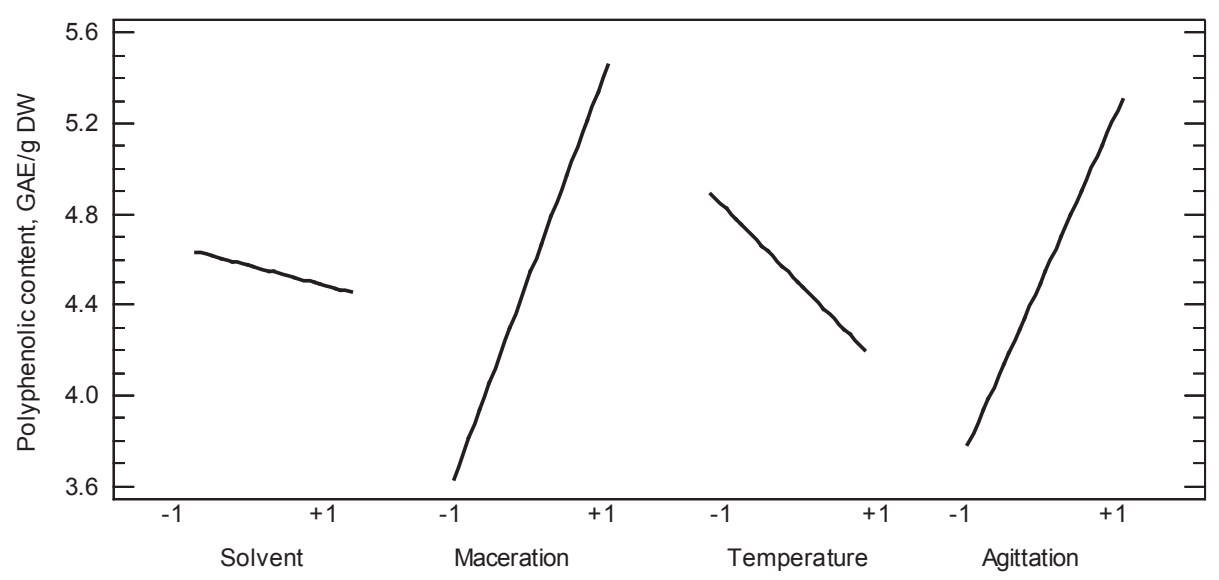

Fig. 6. Effects of the variation of the four main parameters on polyphenolic content efficiency 
Surface de réponse estimée Temperature $=0.0$,Agittation $=0.0$

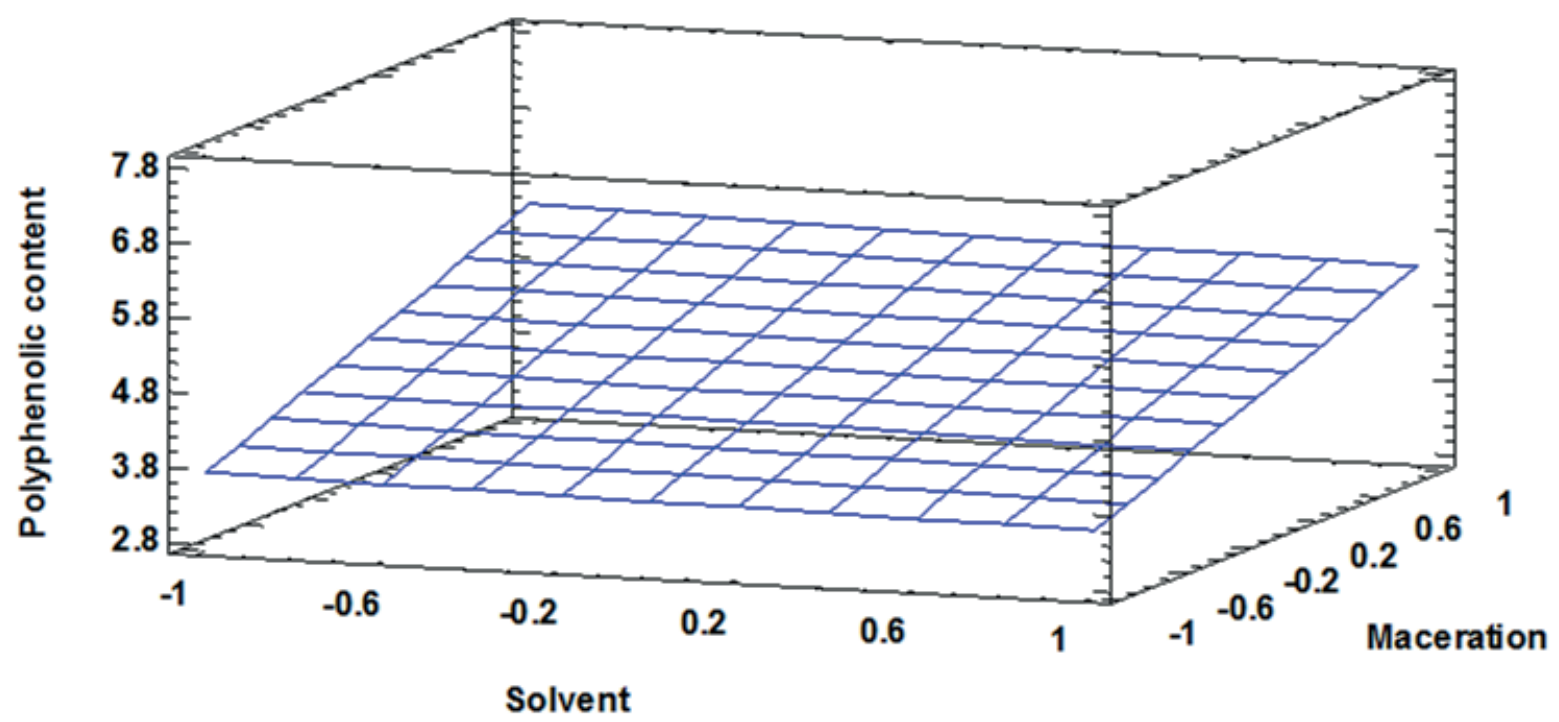

Fig. 7. Response surface for the polyphenolic content as a function of the solvent using and maceration period

is shifted from its lowest level (1) to its highest level $(+1)$. The plot reveals that the efficiency of phenolic compounds extraction decreases as temperature and concentration of solvent increase. The results of this study are similar to those of other authors; Venditti et al. (2010) obtained significantly higher values in white tea after steeping in cold water (RT) for two hours. This study found that extraction of polyphenols was poor for water and aqueous ethanol at $40^{\circ} \mathrm{C}$. In contrast, this parameter shows a positive correlation with maceration period and agitation speed. With the magnitude and direction of the variations of the parameters defined, the parameter settings can be optimized for extraction efficiency. In the present study, response surfaces were used to obtain this information. Figure 7 shows the height of the response surface for solvent extraction efficiency (phenolic content) over the space of the solvent using coating and maceration period, with the other two factors (temperature and agitation) held constant. This figure clearly indicates that the greatest phenolic content was obtained at high values for maceration period and low solvent concentration (methanol 80\%). Addition of some amount of water enhance the extraction efficiency. One possible reason for the increased efficiency with the presence of some water might be due to the increase in bulge of plant material by water, which increased the contact surface area between the plant matrix and the solvent. In addition, among the most significant factors that influence the polyphenol content, the duration of maceration is the one that affects the polyphenol extraction from the plant (Ricardoda-Silva et al., 1993; Sims and Bates, 1994). Extended maceration is known to cause an increase in polyphenol content in plant (Sun et al., 1999).

\section{CONCLUSIONS}

In summary, our results clearly showed that the extraction of phenolic and anthocyanin compounds and their antioxidant capacity is significantly affected by solvent combinations. S. undulata presented the highest total phenolic content, total flavonoids content and antioxidant capacity values. In addition, there was a good correlation between total phenolic content and the antioxidant capacity of the $S$. undulata extracts. Organic solvents were more efficient in extracting antioxidant compounds than their water solvent. This paper presents the application of the design-of experiment 
Athmouni, K., Belghith, T., Bellassouad, K., El Feki, A., Ayadi, H. (2015). Effect of extraction solvents on the biomolecules and antioxidant properties of Scorzonera undulata (Asteraceae): Application of factorial design optimization phenolic extraction. Acta Sci. Pol. Technol. Aliment., 14(4), 313-330. DOI: 10.17306/J.AFS.2015.4.32

method for optimizing the extraction of phenolic content. This method provided answers to several fundamental questions, such as quantifying the most sensitive parameters of the model and their interactions $-\mathrm{a}$ task that is difficult to perform using conventional experimental methods. The resulting regression model has shown that the effect of temperature is not statistically significant (with $>95 \%$ certainty), while that of agitation speed is. The two main effects are contributed by the solvent concentration and the maceration period.

\section{ACKNOWLEDGMENTS}

This work was supported by the research unit biodiversity and aquatic ecosystems in the Faculty of Sciences of Sfax. Thanks are due to Dr. Fawzi Makni for his help in verifying the quality of the manuscript.

\section{REFERENCES}

Addai, Z. R., Abdullah, A., Mutalib, S. A. (2013). Effect of extraction solvents on the phenolic content and antioxidant properties of two papaya cultivars. J. Med. Plants Res., 7, 3354-3359.

Akkol, E. K., Acikara, O. B., Suntar, I., Citoglu, G. S., Keles, H., Ergene, B. (2011). Enhancement of wound healing by topical application of Scorzonera species: Determination of the constituents by HPLC with new validated reverse phase method. J. Ethnopharmacol., 137, 1018-1027.

Akkola, E. K., Acıkarab, Ö. B., Süntara, I. B., Gülc., Saltan, C. (2012). Ethnopharmacological evaluation of some Scorzonera species: In vivo anti-inflammatory and antinociceptive effects. J. Ethnopharmacol., 140, 261-270.

Alothman, M., Bhat, R., Karim, A. A. (2009). UV radiationinduced changes of antioxidant capacity of fresh-cut tropical fruits. Innov. Food Sci. Emerg. Technol., 10, $512-516$.

Amin, I., Zamaliah, M. M., Chin, W. F. (2004). Total antioxidant activity and phenolic content in selected vegetables. Food Chem., 87, 581-586.

Amoateng, P., Koffuor, G. A., Sarpong, K., Kwabena, O. (2011). Free radical scavenging and anti-lipid peroxidative effects of a hydro-ethanolic extract of the whole plant of Synedrella nodiflora (L.) Gaertn (Asteraceae). DOI: $10.5530 / a x .2$.

Anagnostopoulou, M. A., Kefalas, P., Papageorgiou, V. P., Assimopoulou, A. N., Boskou, D. (2006). Radical scavenging activity of various extracts and fractions of sweet orange peel (Citrus sinensis). Food Chem., 94, 19-25.
Auzi, A. R., Hawisa, N. T., Sherif, F. M., Sarker, S. D. (2007). Neuropharmacological properties of Launaea resedifolia. Braz. J. Pharm., 17, 160-165.

Benmeddour, Z., Mehinagic, E., Meurlayb, D. L., Louaileche, H. (2013). Phenolic com-position and antioxidant capacities of ten Algerian date (Phoenix dactylifera L.) cultivars: a comparative study. J. Funct. Foods, 5, 346-354.

Benzie, I. F. F., Strain, J. J. (1996). The ferric reducing ability of plasma (FRAP) as a measure of "antioxidant power”: The FRAP assay. Anal. Biochem., 239, 70-76.

Brewer, M. S. (2011). Natural antioxidants: sources, compounds, mechanism of action, and potential application. Compr. Rev. Food Sci. F, 10, 221-247.

Broadhurst, R. B., Jones, W. T. (1978). Analysis of condesed tannins using acidified vanillin. J. Sci. Food Agric., 29, 788-797.

Burt, S. (2004). Essential oils: Their antibacterial properties and potential applications in foods $-\mathrm{A}$ review. Int. J. Food Microbiol., 94, 223-253.

Chen, T., He, J., Zhang, J., Li, X., Zhang, H., Hao, J., Li, L. (2012). The isolation and identification of two compounds with predominant radical scavenging activity in hempseed (seed of Cannabis sativa L.). Food Chem., 134, 1030-1037.

Chopra, S., Athma, P., Peterson, T. (1996). Alleles of the maize Pgene with distinct tissue specificities encode Myb-homologous proteins with C-terminal replacements. The Plant Cell, 8, 1149-1158.

Cotelle, N., Bernier, J. L., Catteau, J. P., Pommery, J., Wallet, J. C., Gaydou, E. M. (1996). Antioxidant properties of hydroxy-flavones. Free Radic. Biol. Med., 20, 35-43.

Dorman, H. J. D., Peltoketo, A., Hiltunen, R., Tikkanen, M. J. (2003). Characterisation of the antioxidant properties of de-odourised aqueous extracts from selected Lamiaceae herbs. Food Chem., 83, 255-262.

Erden, Y., Kırbag, S., Y1lmaz, O. (2013). Phytochemical composition and antioxidant activity of some Scorzonera species. Proc. Natl. Acad. Sci., India, Sect. B, Biol. Sci., 83, 271-276.

Fernandez-Arroyo, S., Rodriguez-Medina, I. C., Beltran-Debon, R., Pasini, F., Joven, J., Micol, V., Segura-Carretero, A., Fernandez-Gutierrez, A. (2011). Quantification of the polyphenolic fraction and in vitro antioxidant and in vivo anti-hyperlipemic activities of Hibiscus sabdariffa aqueous extract. Food Res. Int., 44, 1490-1495.

Galher, S., Otto, K., Böhm, V. (2003). Alterations of vitamin $\mathrm{C}$, total phenolics, and antioxidant capacity as affected by processing tomatoes to different products. J. Agric. Food Chem., 51, 7962-7968.

Ghasemzadeh, A., Ghasemzadeh, N. (2011). Flavonoids and phenolic acids: Role and biochemical activity in plants and human. J. Med. Plants Res., 5, 6697-6703. 
Athmouni, K., Belghith, T., Bellassouad, K., El Feki, A., Ayadi, H. (2015). Effect of extraction solvents on the biomolecules and antioxidant properties of Scorzonera undulata (Asteraceae): Application of factorial design optimization phenolic extraction. Acta Sci. Pol. Technol. Aliment., 14(4), 313-330. DOI: 10.17306/J.AFS.2015.4.32

Gorinstein, S., Vargas, O. J. M., Jaramillo, N. O., Salas, I. A., Ayala, A. L. M., Arancibia-Avila, P., Toledo, F., Katrich, E., Trakhtenberg, S. (2007). The total polyphenols and the antioxidant potentials of some selected cereals and pseudocereals. Eur. Food Res. Technol., 225, 321-328.

Gouveia, S., Gonc, J., Castilho, P. C. (2013). Characterization of phenolic compounds and antioxidant activity of ethanolic extracts from flowers of Andryala glandulosa ssp. varia (Lowe ex DC.) R. Fern., an endemic species of Macaronesia region. Ind. Crop. Prod., 42, 573-582.

Guo, B., Gao, M., Liu, C. Z. (2007). In vitro propagation of an endangered medicinal plant Saussurea involucrate Kar. et Kir. Plant Cell Rep., 26, 261-265.

Hirasa, K., Takemasa, M. (1998). Spice science and technology. New York: Marcel Dekker.

Holton, T. A., Cornish, E. C. (1995). Genetics and biochemistry anthocynin biosynthesis. The Plant Cell., 7, 1071-1083.

Hou, D. X., Fujii, M., Terahara, N., Yoshimoto, M. (2004). Molecular mechanisms behind the chemopreventive effects of anthocyanidins. J. Biomed. Biotechn., 5, $321-325$

Hou, W. C., Lin, R. D., Cheng, K. T., Hung, Y. T., Cho, C. H., Chen, C. H., Hwang, S. Y., Lee, M. H. (2003). Free radical scavenging activity of Taiwanese native plants. Phytomedicine, 10, 170-175.

Hsu, B., Coupar, I. M., Ken, N. (2006). Antioxidant activity of hot water extract from the fruit of the Doum palm, Hyphaene thebaica. Food Chem., 98, 317-328.

Jehle, M., Bano, J., Ellmerer, E. P., Zidorn, C. (2010). Natural products from Scorzonera aristata (Asteraceae). Nat. Prod. Commun., 5, 725-727.

Jiang, T. F., Wang, Y. H., Lv, Z. H., Yue, M. E. (2007). Determination of kava lactones and flavonoid glycoside in Scorzonera austriaca by capillary zone electrophoresis. J. Pharm. Biomed. Anal., 43, 854-858.

Kamran, G., Youcef, G., Ebrahimzadeh, M. A. (2009). Antioxydant activity, phenol and flavonoid contents of 13 citrus species peels and tissues. Pak. J. Pharm. Sci., 22, 277-281.

Kenny, O., Smyth, T. J., Walsh, D., Kelleher, C. T., Hewage, C. M., Brunton, N. P. (2014). Investigating the potential of under-utilised plants from the Asteraceae family as a source of natural antimicrobial and antioxidant extracts. Food Chem., 161, 79-86. DOI: http://dx.doi. org/10.1016/j.foodchem.2014.03.126.

Khadri, A., Neffati, M., Smiti, S., Falé, P., Lona, A. R. L., ..., Serralheiro, M. L. M. (2010). Antioxidant, antiacetylcholinesterase and antimicrobial activities of Cymbopogon schoenanthus L. Spreng (lemon grass) from Tunisia. Food Sci. Technol., 43, 331e6.

Khlifi, D., Sghaier, R. M., Amouri, S., Laouini, D., Hamdi, M., Bouajila, J. (2013). Composition and anti-oxidant, anti-cancer and anti-inflammatory activities of Artemisia herba-alba, Ruta chalpensis L. and Peganum harmala L. Food Chem. Toxicol., 55, 202-208.

Kim, D.-K., Jeong, S. W., Lee, C. Y. (2003). Antioxidant capacity of phenolic phytochemicals from various cultivars of plums. Food Chem., 81, 321-326.

Konczak-Islam, I., Yoshimoto, M., Hou, D. X., Terahara, N., Yamakawa, O. (2003). Chemopreventive properties of anthocyanin-rich aqueous extracts from in vitro produced tissue of sweetpotato (Ipomoea batatas L.). J. Agric. Food Chem., 51, 5916-5922.

Kong, J. M., Chia, L. S., Goh, N. K., Chia, T. F., Brouillard, R. (2003). Analysis and biological activities of anthocyanins. Phytochemistry, 64, 923-933.

Lahouel, M., Fillastre, J. P. (2004). Role of flavonoids in the prevention of haematotoxicity due to chemotherapeutic agents. Haema, 7(3), 313-320.

LeBlanc, B. W., Davis, O. K., Boue, S., DeLucca, A., Deeby, T. (2009). Antioxidant activityof Sonoran Desert bee pollen. Food Chem., 115, 1299-1305.

Leon, M. A., Kumar, S. (2007). Mathematical modeling and thermal performance analysis of unglazed transpired solar collectors. Solar Ener., 81, 62-75.

Li, S., Li, S.-K., Gan, R.-Y., Song, F.-L., Kuang, L., Li, H.-B. (2013). Antioxidant capacities and total phenolic contents of infusions from 223 medicinal plants. Ind. Crop. Prod., 51, 289-298.

Lixiang, L., Yi, S., Tanguy, L., Xingfei, L., Hong, Y., Xiaoxiong, Z. (2009). Determination of polyphenolic content and antioxidant activity of kuding chamade from Ilex kudingcha C. J. Tseng. Food Chem., 112, 35-41.

Mailoa, M. N., Mahendradatta, M., Laga, A., Djide N. (2013). Tannin extract of Guava leaves (Psidium Guajava L.) variation with concentration organic solvents. Int. J. Sci. Techn. Res., 2, 9, 106-110.

Matthäus, B. (2002). Antioxidant activity of extracts obtained from residues of different oilseeds. J. Agric. Food Chem., 50, 3444-3452.

Myers, J. P., vom Saal, F. S., Akingbemi, B. T., Arizono, K., Belcher, S., ..., Colborn, T. (2009). Why public health agencies cannot depend on Good Laboratory Practices as a criterion for selecting data: the case of bisphenol A. Environ. Health Perspect., 117, 309-315.

Milella, L., Bader, A., Tommasi, N. D., Russo, D., Braca, A. (2014). Antioxidant and free radical-scavenging activity of constituents from two Scorzonera species. Food Chem., 160, 298-304. DOI.org/10.1016/j.foodchem

Mol, J., Grotewold, E., Koes, R. (1998). How genes paint flowers and seeds. Trends Plant Sci., 3, 212-217.

Molyneux, P. (2004). The use of the stable free radical diphenylpicrylhydrazyl (DPPH) for estimating antioxidant activity. Songklanak. J. Sci. Techn., 26, 211-219.

Mothana, R. A. A. (2011). Anti-inflammatory, antinociceptive and antioxidant activities of the endemic Soqotraen Boswellia elongata Balf. and Jatropha unicostata Balf. 
Athmouni, K., Belghith, T., Bellassouad, K., El Feki, A., Ayadi, H. (2015). Effect of extraction solvents on the biomolecules and antioxidant properties of Scorzonera undulata (Asteraceae): Application of factorial design optimization phenolic extraction. Acta Sci. Pol. Technol. Aliment., 14(4), 313-330. DOI: 10.17306/J.AFS.2015.4.32

in different experimental models. Food. Chem. Toxicol., 49, 2594-2599.

Naczk, M., Shahidi, F. (2004). Extraction and analysis of phenolics in food. J. Chromat., 1054, 95-111.

Nsimba, R. Y., Kikuzaki, H., Konishi, Y. (2008). Antioxidant activity of various extracts and fractions of Chenopodium quinoa and Amaranthus spp. seeds. Food Chem., 106, 760-766.

Okuda, T. (1999). Novel aspects of tannins - Renewed concepts and structure-activity relationships. Curr. Org. Chem., 3, 609-622.

Okuda, T., Yoshida, T., Hatano, T. (1991). Chemistry and biological activities of tannins in medicinal plants. In H. Wagner, N. R. Farnsworth (Eds.), Economic and medicinal plants research. Vol. 5 (pp. 129-165). New York: Academic Press.

Okuda, T., Yoshida, T., Hatano, T. (1992). Pharmacologically active tannins isolated from medicinal plants. In R. W. Hemingway, P. E. Laks (Eds.), Plant polyphenols: biogenesis, chemical properties and significance (pp. 539-569). New York: Plenum Press.

Okuda, T., Yoshida, T., Hatano, T. (1995). Hydrolyzable tannins and related polyphenols. In W. Herz, G. W. Kirby, R. E. Moore, W. Steglich, C. Tamm (Eds.), Progress in the chemistry of organic natural products. Vol. 66. Wien, New York: Springer.

Okuda, T., Yoshida, T., Mori, K. (1975). Studies on the constituents of Geranium thunbergii II. Yakugaku Zasshi, 95, 1462-1466.

Ouchemoukhe, S., Hachoud, S., Boudrahama, H., Mokrani, A., Louaileche, H. (2012). Antioxidant activities of some dried fruits consumed in Algeria. LWT - Food Sci. Technol., 49, 329-332.

Oyaizu, M. (1986). Studies on product of browning reaction prepared from glucose amine. Jpn J. Nutr., 44, 307-315.

Ozgen, M., Reese, R. N., Tulio, A. Z., Miller, A. R., Scheerens, J. C. (2006). Modified 2,2-azino-bis-3-ethylbenzothiazoline-6-sulfonic acid (ABTS) method to measure antioxidant capacity of selected small fruits and comparison to ferric reducing antioxidant power (FRAP) and 2,2-diphenyl-1-picrylhydrazyl (DPPH) methods. J. Agric. Food Chem., 54, 1151-1157.

Ozsoy, N., Yilmaz, T., Kurt, O., Can, A. (2009). In vitro antioxidant activity of Amaranthus lividus L. Food Chem., 116, 867-872.

Oztürk, H., Kolak, U., Meric, C. (2011). Antioxidant, anticholinesterase and antibacterial activities of Jurinea consanguinea DC. Rec. Nat. Prod., 5, 43-51.

Prochazkova, D., Bousova, I., Wilhelmova, N. (2011). Antioxidant and prooxidant properties of flavonoids, Fitoterapia, 82, 513-523.

Ramful, D., Tarnus, E., Aruoma, O. I., Bourdon, E., Bahorun, E. (2011). Polyphenol composition, vitamin C content and antioxidant capacity of Mauritian citrus fruitpulps. Food Res. Int., 44, 2088-2099.

Ramos-Escudero, F., María, L., Gonzalez-Miret, A., Garcia-Asuero, A. (2012). Effect of various extraction systems on the antioxidant activity kinetic and color of extracts from Purple Corn. Vittae Revista de la Facultad de Quimica Farmaceutica, 19, 1, 41-48.

Ricardo-da-Silva, J. M., Cheynier, V., Samsom, A., Bourzeix, M. (1993). Effect of pomace contact, carbonic maceration, and hyperoxidation on the procyanidin composition of Grenache blanc wines. Am. J. Enol. Vitic., 44, 168-172.

Robards, K., Prenzler, P. D., Tucker, G., Swatsitang, P., Glover, W. (1999). Phenolic compounds and their role in oxidative processes in fruits. Food Chem., 66, 401-436.

Rout, G. R., Samantaray, S., Das, P. (2000). In vitro manipulation and propagation of medicinal plants. Biotechn. Adv., 18, 2, 91-120.

Sareedenchai, V., Zidorn, C. (2010). Flavonoids as chemosystematic markers in the tribe Cichorieae of the Asteraceae. Biochem. Syst. Ecol., 38, 935-957.

Sari, A. (2012). Phenolic compounds from Scorzonera latifolia (Fisch \& Mey) DC. Nat. Prod. Res., 26, 50-55.

Sari, A., Zidorn, C., Ellmerer L. P., Özgökçe F., Onganiac, K. H., Stuppner, H. (2007). Phenolic compounds from Scorzonera tomentosa L. Helv. Chim. Acta, 90, 311-317.

Shahat, A. A., Ibrahim, A. Y., Elsaid, M. S. (2014). Polyphenolic content and antioxidant activity of some wild Saudi Arabian Asteraceae plants. Asian Pac. J. Trop. Biomed., 7(7), 545-551.

Shinde, A. N., Malpathak, N., Fulzele, D. P. (2010). Determination of isoflavone and antioxidant activity in Psoralea corylifolia L. callus cultures. Food Chem., 118, 128-132.

Sims, C. A., Bates, R. P. (1994). Comparison of pre-fermentation and post-fermentation ultrafiltration on the characteristics of sulfited and non-sulfited white wines. Am. J. Enol. Vitic., 45, 182-185.

Singleton, V. L., Rossi, J. A. (1965). Colorimetry of total phenolics with phosphomolybdic-phosphotungstic acid reagents. Am. J. Enol. Vitic., 16, 144-158.

Škrovánková, S., Mišurcová, L., Machů, L. (2012). Antioxidant activity and protecting health effects of common medicinal plants. Adv. Food Nutr. Res., 67, 75-139.

Stintzing, F. C., Carle, R. (2004). Functional properties of anthocyanins and betalains in plants, food, and in human nutrition. Trends Food Sci. Technol., 15, 19-38.

Suhaj, M. (2006). Spice antioxidants isolation and their antiradical activity: A review. J. Food Comp. Anal., 19, 531-537.

Sultana, B., Anwar, F., Przybylski, R. (2007). Antioxidant activity of phenolic components present in barks of Azadirachta indica, Terminalia arjuna, Acacia nilotica, 
Athmouni, K., Belghith, T., Bellassouad, K., El Feki, A., Ayadi, H. (2015). Effect of extraction solvents on the biomolecules and antioxidant properties of Scorzonera undulata (Asteraceae): Application of factorial design optimization phenolic extraction. Acta Sci. Pol. Technol. Aliment., 14(4), 313-330. DOI: 10.17306/J.AFS.2015.4.32

and Eugenia jambolana lam trees. Food Chem., 104, 1106-1114.

Sun, Y., Liu, D., Chen, J., Ye, X., Yu, D. (2011). Effects of different factors of ultrasound treatment on the extraction yield of the all-trans- $\beta$-carotene from citrus peels. Ultrason. Sonochem., 18, 243-249.

Sun, B. S., Pinto, T., Leandro, M. C., Ricardo da Silva, J. M., Spanger, M. I. (1999). Transfer of catechins and proanthocyanidins from grape solids into wine. Am. J. Enol. Vitic., 50, 179-184.

Tai, Z., Cai, L., Dai, L., Dong, L., Wang, M., Yang, Y., Cao, Q., Ding, Z. (2011). Antioxidantactivity and chemical constituents of edible flower of Sophora viciifolia. Food Chem., 126, 1648-1654.

Tsevegsuren, N., Edrada, R., Lin, W., Ebel, R., Torre, C., ..., Ortlepp, S., (2007). Biologically active natural products from Mongolian medicinal plants Scorzonera divaricata and Scorzonera pseudodivaricata. J. Nat. Prod., 70, 962-967.

Tsevegsuren, N., Edrada, R. A., Lin, W., Ebel, R., Torre, C., ..., Proksch, P. (2007). Four new natural products from mongolian medicinal plants Scorzonera divaricata and Scorzonera pseudodivaricata (Asteraceae). Plant. Med., 72, 962-967.

Turkmen, N., Sari, F., Velioglu, Y. S. (2006). Effect of extraction solvents on concentration and antioxidant activity of black and black mate polyphenols determined by ferrous tartrate and Folin-Ciocalteu methods. Food Chem., 99, 838-841.

Velioglu, Y. S., Mazza, G., Gao, L., Oomah, B. D. (1998). Antioxidant activity and total phenolics in selected fruits, vegetables, and grain products. J. Agric. Food Chem., 46, 4113-4117.

Venditti, E., Bacchetti, T., Tiano, L., Carloni, P., Greci, L., Damiani, E. (2010). Hot vs. cold water steeping of different teas: Do they affect antioxidant activity? Food Chem., 119, 1597-1604.

Vuong, Q. V., Hirun, S., Roach, P. D., Bowyer, M. C., Phillips, P. A., Scarlett, C. J. (2013). Effect of extraction conditions on total phenolic compounds and antioxidantactivities of Carica papaya leaf aqueous extracts. J. Herb. Med., 3, 104-111.

Wang, B., Li, G. Q., Qui, P. J., Guan, H. S. (2007). Two new oleane-type triterpene fatty esters from Scorzonera mongolica. Chinese Chem. Lett., 18, 708-710.
Wang, Y., Wray, V., Tsevegsuren, N., Lin, W. H., Proksch, P. (2012). Phenolic compounds from the Mongolian medicinal plant Scorzonera radiata. Z. Naturforsch. C, 67, 135-143.

WHO, IUCN, WWF (1993). Guidelines on the conservation of medicinal plants. Gland, Geneva, Switzerland: IUCN, WHO, WWF.

Wojdyło, A., Oszmiański, J., Czemerys, R. (2007). Antioxidant activity and phenolic compounds in 32 selected herbs. Food Chem., 105, 940-949.

Xi, J., Shen, D., Zhao, S., Lu, B., Li, Y., Zhang, R. (2009). Characterization of polyphenolsfrom green tea leaves using a high hydrostatic pressure extraction. Int. J. Pharm., 382, 139-143.

Yang, Y. J., Liu, X., Wu, H. R., He, X. F., Bi, Y. R., ..., Zhu, Y. (2013). Radical scavenging activity and cytotoxicity of active quinic acid derivatives from Scorzonera divaricata roots. Food Chem., 138, 2057-2063.

Yesil-Celiktas, O., Nartop, P., Gurel, A., Bedir, E., VardarSukan, F. (2007). Determination of phenolic content and antioxidant activity of extracts obtained from Rosmarinus officinalis calli. J. Plant Physiol., 164, 1536-1542.

Zhang, P., Jin, Y., Chen, J., Yao, H., Zhang, H., Yu, A., Li, X. (2013). Ultrasonic-assisted nebulization extraction coupled with SPE and HPLC for the determination of triterpenoids in root of Euphorbia pekinensis Rupr. Chromatographia, 76, 967-974.

Zhishen, J., Mengcheng, T., Jianming, W. (1999). The determination of flavonoid contents in mulberry and their scavenging effects on superoxide radicals. Food Chem., 64, 555-559.

Zhu, Y., Wu, Q., Hu, P., Wu, W. (2009). Biguaiascorzolides $\mathrm{A}$ and B: two novel dimeric guaianolides with a rare skeleton, from Scorzonera austriaca. Food Chem., 114, $1316-1320$.

Zidorn, C. (2008). Sesquiterpene lactones and their precursors as chemo systematic markers in the tribe Cichorieae of the Asteraceae. Phytochemistry, 69, 2270-2296.

Zidorn, C., Ellmerer, E. P., Sturm, S., Stuppner, H. (2003). Tyrolobibenzyls E and F from Scorzonera humilis and distribution of caffeic acid derivatives, lignans and tyrolobibenzyls in European taxa of the subtribe Scorzonerinae (Lactuceae, Asteraceae). Phytochemistry, 63, 61-67.

Zidorn, C., Ellmerer-Müller, E. P., Stuppner, H. (2000). Tyrolobibenzyls-novel secondary metabolites from Scorzonera humilis L. Helv. Chim. Acta, 83, 2920-2925.

Athmouni, K., Belghith, T., Bellassouad, K., El Feki, A., Ayadi, H. (2015). Effect of extraction solvents on the biomolecules and antioxidant properties of Scorzonera undulata (Asteraceae): Application of factorial design optimization phenolic extraction. Acta Sci. Pol. Technol. Aliment., 14(4), 313-330. DOI: 10.17306/J.AFS.2015.4.32 